This is a peer-reviewed, accepted author manuscript of the following research article/chapter/conference paper:

Fan, F., Li, Y., Ziani, S., \& Stewart, B. G. (Accepted/In press). Reversible substation modelling with regenerative braking in DC traction power supply systems. Paper presented at The 5th Annual IEEE Texas Power and Energy Conference, College Station, United States.

\title{
Reversible Substation Modelling with Regenerative Braking in DC Traction Power Supply Systems
}

\author{
Fulin Fan \\ Institute for Energy and \\ Environment \\ University of Strathclyde \\ Glasgow, United Kingdom \\ f.fan@strath.ac.uk
}

\author{
Yafang $\mathrm{Li}$ \\ IRT Railenium \\ Valenciennes, France \\ yafang.li@railenium.eu
}

\author{
Smail Ziani \\ IRT Railenium \\ Valenciennes, France \\ smail.ziani@railenium.eu
}

\author{
Brian G. Stewart \\ Institute for Energy and \\ Environment \\ University of Strathclyde \\ Glasgow, United Kingdom \\ brian.stewart.100@strath.ac.uk
}

\begin{abstract}
Compared to traditional unidirectional substations, a reversible substation (RSS) permitting bidirectional power flows is an efficient approach to recovering the braking energy of trains and increasing the energy efficiency of DC traction power supply systems (TPSS). This paper develops two models to reflect the role of an RSS under high and low fidelities, focusing on the converterand TPSS-level simulation respectively. A particular RSS topology consisting of a 12-pulse diode rectifier and an antiparallel active neutral point clamped voltage source inverter (VSI) is replicated in a high-fidelity model where the VSI is controlled to maintain a constant DC voltage in the braking mode. To reduce computation burden, a low-fidelity model simplifies the rectifier into a diode in series with a controlled voltage source (CVS) that reflects its nonlinear output characteristics, and connects a DC voltage source in parallel with the CVS branch, permitting the delivery of braking power to the RSS under the constant DC voltage control. The two models are tested based on a simplified $1.5 \mathrm{kV}$ TPSS and discussed alongside the consistency in the simulation of the power exchange and voltage transients at the RSS in traction and braking modes.
\end{abstract}

Keywords-active neutral point clamped inverter, constant DC voltage control, regenerative braking, reversible substation, traction power supply system.

\section{INTRODUCTION}

As the transition to a low-carbon energy system, increasing the energy efficiency of European railway systems is required to meet the target of reducing $30 \%$ of their specific final energy usage and half of average $\mathrm{CO}_{2}$ emissions from train operation by 2030 compared to the 1990 base year [1]. The installation of a reversible substation (RSS) that permits bidirectional power flows is expected to be an efficient approach to improving the energy efficiency of a DC traction power supply system (TPSS). The RSS can recover the surplus regenerative braking energy of trains [2] which would otherwise be dissipated as heat in braking resistors so as to avoid the exceedance of the over-voltage limit of a TPSS [3]. The regenerative braking energy fed-back-to AC sides can be consumed by AC equipment in an RSS or even sold back to electricity suppliers depending on local legislations and rules of electrical grids $[2,4]$.

The research was developed in the framework of the 16ENG04 MyRails Project which received funding from the EMPIR Programme co-financed by the Participating States and from the European Union's Horizon 2020 Research and Innovation Programme.
In a DC TPSS equipped with conventional unidirectional substations (USS), an RSS can be achieved either by connecting an inverter in antiparallel with the existing diode rectifier at a USS or by replacing the rectifier with a bidirectional converter directly $[2,3]$. Compared to the former solution which provides the reverse path using minimal equipment, the need of changing the existing transformer makes the latter solution more complex and expensive $[2,3]$. Considering the costly investment in an $\mathrm{RSS}$, it is necessary to simulate the power exchange between $\mathrm{AC}$ and DC sides and then quantify the benefits associated with the braking energy recovered by the RSS [5]. This focuses more on the TPSS-level simulation over a long time period (e.g. from minutes [6] to hours [7]). The simulation generally adopts a relatively long time step (e.g. 1-s [6,7]) and simplifies the substation representation $[5,8]$ so as to alleviate the computation burden at a cost of a reduced fidelity.

In addition to quantifying the braking energy recovery, the effectiveness of the control algorithm applied to an RSS and its impacts on power quality and system stability must be evaluated in advance [9] by analysing the voltage and current transients on $\mathrm{AC}$ and DC sides. The transient analysis generally relies on the converter-level simulation which requires to replicate converter topologies and use a short time step (e.g. 5- $\mu$ s $[9,10])$ to ensure a sufficient fidelity in the simulation.

To achieve the two different simulation objectives, this paper develops two models with different fidelities to simulate the role of an RSS. A high-fidelity model replicates a particular topology of an RSS where a 12-pulse diode rectifier is connected in antiparallel with a three-level active neutral point clamped (ANPC) voltage source inverter (VSI) rather than a traditional two-level VSI which has been studied in most research related to RSS simulation [9]-[12]. Compared with a droop control, a constant DC voltage control method was shown to increase the recovery of braking energy [12] and is therefore used here to manage the VSI in the braking mode. In a low-fidelity model, the 12-pulse rectifier is simplified into a diode and a controlled voltage source (CVS) taking into account the non-linear output characteristic of the rectifier; the ANPC VSI along with the constant DC voltage control method is replaced with a DC voltage source in parallel with the CVS branch. The two models will be demonstrated here based on a simplified $1.5 \mathrm{kV}$ DC TPSS which comprises a single RSS and a single train only for brevity. 
The paper is structured as follows: Section II describes the high-fidelity model along with the control method applied to the ANPC VSI; Section III introduces the simplified representation of converters in the low-fidelity model as well as the simulation of a train moving along an overhead line; Section IV compares the two models in the simulation of the power exchange and DC voltage transient at the RSS; and Section V presents conclusions and recommendations for further work.

\section{High-Fidelity MODEL OF REVERSIBLE SUBSTATION}

\section{A. Converter Topologies at Reversible Substation}

The topology of a particular RSS including a 12-pulse diode rectifier and an antiparallel ANPC VSI is shown in Fig. 1. The two secondary windings of the transformer $A$ supplying the 12pulse rectifier are Delta and Star connected respectively to create a phase difference of 30 degrees. In the traction mode, the two phase displaced, three-phase $\mathrm{AC}$ voltages are supplied to two 6pulse rectifiers operating in parallel to generate a 12-pulse ripple in the DC output voltage [2], which supports the train operation via a third rail or an overhead catenary line. In the braking mode, the surplus regenerative braking energy of a train fed-to the line increases the line voltage; when the voltage $V_{R S S}$ across the RSS reaches a specific level $V_{V S I, a c t}$ of $1780 \mathrm{~V}$, the VSI is activated to transfer the braking power to the AC side while maintaining a constant DC voltage at $V_{V S I, a c t}$ in this work. Compared to a conventional two-level VSI topology [13], a three-level neutral point clamped (NPC) VSI employs four switching devices, e.g. insulated-gate bipolar transistors (IGBTs) per phase and two additional diodes which link the midpoint of the two IGBTs to the neutral point of the VSI [14], producing a three-level voltage waveform on the AC side. An ANPC VSI further replaces the two passive diodes in the NPC VSI with IGBTs (see Fig. 1) that are actively controlled to improve loss distributions and equalise stresses across IGBTs [15]. When no braking current is fed back to the RSS (i.e. $I_{R S S} \geq 0$ ), the VSI will be deactivated.

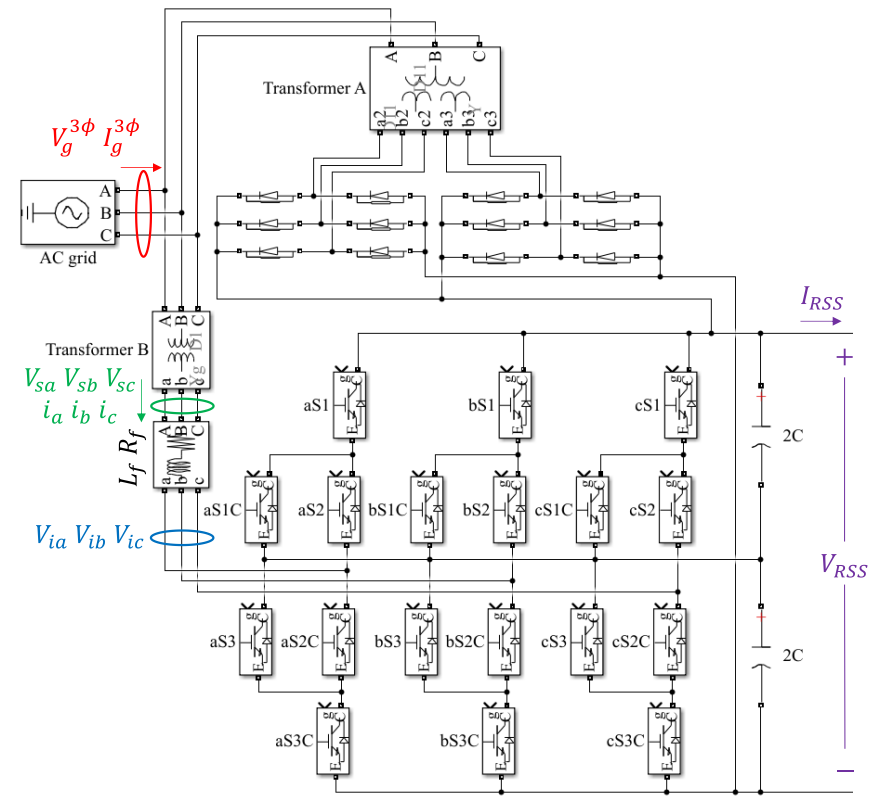

Fig. 1. A particular RSS topology comprising a twelve-pulse diode rectifier and a three-level ANPC VSI in a high-fidelity model.
Technical parameters of the RSS modelled here are tabulated in Table I. It is noted that an RSS is generally equipped with two identical sets of rectifying and inverting equipment which are parallel connected to improve the system capacity and reliability [9]. In this study, a single equipment unit is modelled for brevity. In addition, $V_{V S I, a c t}=1780 \mathrm{~V}$ is higher than the no-load voltage of the rectifier (i.e. $\sqrt{2} \times 1225 \approx 1732.41 \mathrm{~V}$ ). This creates a deadband for the transition between inverting and rectifying [16], avoiding the current circulation between the rectifier and the VSI. The three-phase voltage $V_{g}^{3 \phi}$ and current $I_{g}^{3 \phi}$ simulated at the $\mathrm{AC}$ grid are used to calculate the power exchange between $\mathrm{AC}$ and $\mathrm{DC}$ sides via the RSS.

TABLE I. TECHNICAL PARAMETERS OF THE RSS

\begin{tabular}{|c|c|c|c|}
\hline Parameter & Value & Parameter & Value \\
\hline TX A Volt. & $15 \mathrm{kV} / 2 \times 1225 \mathrm{~V}$ & TX Power & $3.3 \mathrm{MVA}$ \\
\hline TX B Volt. & $15 \mathrm{kV} / 690 \mathrm{~V}$ & TX Resistance & 0.0065 p.u. \\
\hline$R_{f}$ & $2 \mathrm{~m} \Omega$ & TX Inductance & 0.0571 p.u. \\
\hline$L_{f}$ & $0.25 \mathrm{mH}$ & $C$ & $30 \mathrm{mF}$ \\
\hline
\end{tabular}

\section{B. Constant DC Voltage Control and AC Current Control}

The output phase voltages $V_{i a}, V_{i b}$ and $V_{i c}$ of the VSI (see Fig. 1) can be formulated by (1) based on the phase voltages $V_{s a}$, $V_{s b}$ and $V_{s c}$ on the secondary side of the transformer $B$.

$$
\left\{\begin{array}{l}
V_{i a}=V_{s a}-\left(R_{f}+L_{f} \cdot \frac{d}{d t}\right) \cdot i_{a} \\
V_{i b}=V_{s b}-\left(R_{f}+L_{f} \cdot \frac{d}{d t}\right) \cdot i_{b} \\
V_{i c}=V_{s c}-\left(R_{f}+L_{f} \cdot \frac{d}{d t}\right) \cdot i_{c}
\end{array}\right.
$$

where $R_{f}$ and $L_{f}$ are the filter resistance and inductance placed at the VSI output, and $i_{a}, i_{b}$ or $i_{c}$ denotes the phase current with a negative value indicating the flow from the VSI to transformer $B$. In order to facilitate the design of a VSI control method which generally requires constant quantities in the steady state [17], the electrical variables oscillating in the three-phase $(a b c)$ reference frame are converted into a direct-quadrature-zero $(d q 0)$ rotating reference frame by using the Clarke and Park transforms [18]. Then (1) can be translated into:

$$
\left\{\begin{array}{l}
V_{i d}=V_{s d}-\left(R_{f}+L_{f} \cdot \frac{d}{d t}\right) \cdot i_{d}+w \cdot L_{f} \cdot i_{q} \\
V_{i q}=V_{s q}-\left(R_{f}+L_{f} \cdot \frac{d}{d t}\right) \cdot i_{q}-w \cdot L_{f} \cdot i_{d}
\end{array}\right.
$$

where the electrical variables with subscripts $d$ and $q$ represent their respective direct and quadrature components, and $w$ is the angular frequency of the grid. In the braking mode, a constant DC voltage control method will reduce the difference between the monitored $V_{R S S}$ and the reference $V_{V S I}$,act by a proportionalintegral (PI) controller (see Fig. 2) which exports a reference for $i_{d}$ (denoted by $i_{d}^{*}$ ) taking account of the power balance between DC and AC sides of the VSI [12]. The term $V_{s d}^{r}$ in Fig. 2 denotes the rated value of $V_{s d}$.

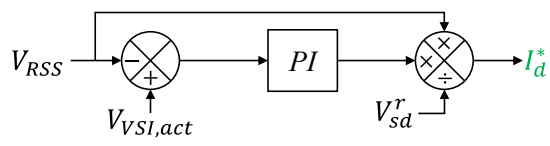

Fig. 2. Scheme of the constant DC voltage control method. 
The VSI is presumed here to operate at a unity power factor, which is achieved by forcing the reference of $i_{q}$ (denoted by $i_{q}^{*}$ ) to zero [19]. Then an AC current control method compares $i_{d}$ and $i_{q}$ with their respective $i_{d}^{*}$ and $i_{q}^{*}$ and uses two identical PI controllers to produce the references for $V_{i d}$ and $V_{i q}$ (denoted by $V_{i d}^{*}$ and $V_{i q}^{*}$ ) based on (2), as shown in Fig. 3. The PI controller parameters, i.e. $K_{P}^{D}$ and $K_{I}^{D}$ for the constant DC voltage control and $K_{P}^{A}$ and $K_{I}^{A}$ for the AC current control are determined by (3) based on a damping factor $\xi=0.707$ and the settling time of $t_{s}^{D}=50 \mathrm{~ms}$ and $t_{s}^{A}=1 \mathrm{~ms}$ respectively at which the secondorder systems are considered to have reached the steady state within an allowable error of $\varepsilon=5 \%$ [17].

$$
\left\{\begin{array} { l } 
{ K _ { P } ^ { D } = 2 \cdot \xi \cdot C \cdot w _ { n } ^ { D } } \\
{ K _ { I } ^ { D } = ( w _ { n } ^ { D } ) ^ { 2 } \cdot C }
\end{array} \quad \left\{\begin{array}{l}
K_{P}^{A}=2 \cdot \xi \cdot L_{f} \cdot w_{n}^{A}-R_{f} \\
K_{I}^{A}=\left(w_{n}^{A}\right)^{2} \cdot L_{f}
\end{array}\right.\right.
$$

where $C$ is the equivalent capacitance across the VSI input, and $w_{n}^{D}$ or $w_{n}^{A}$ is the natural frequency of the second-order system in the constant $\mathrm{DC}$ voltage or the $\mathrm{AC}$ current control respectively:

$$
w_{n}^{D}=-\frac{\ln (\varepsilon)}{\xi \cdot t_{s}^{D}} \quad w_{n}^{A}=-\frac{\ln (\varepsilon)}{\xi \cdot t_{s}^{A}}
$$

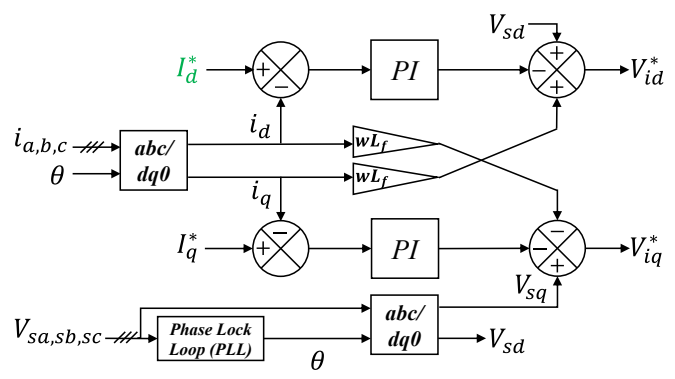

Fig. 3. Scheme of the AC current control method.

Then $V_{i d}^{*}$ and $V_{i q}^{*}$ in the $d q 0$ rotating reference frame need to be converted into $V_{i a}^{*}, V_{i b}^{*}$ and $V_{i c}^{*}$ in the $a b c$ reference frame by using the inverse Clarke and inverse Park transformations [18]. In a particular pulse width modulation (PWM) strategy designed for the ANPC VSI [20], each phase voltage reference (in p.u.) is compared with two carrier waves that are shifted by half of one switching period (i.e. $T_{s w} / 2$ ) to determine the states of the six IGBTs on that phase, producing six switching states $\left(P, O_{1}^{+}, O_{2}^{+}\right.$, $\left.\mathrm{O}_{2}^{-}, \mathrm{O}_{1}^{-}, \mathrm{N}\right)$ as shown in Fig. 4. This leads to a natural doubling of the apparent switching frequency [20].
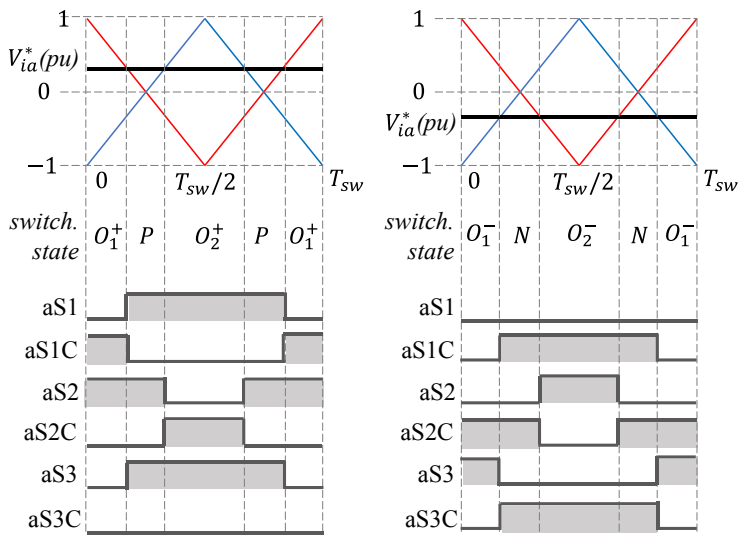

Fig. 4. The PWM strategy applied to a three-level ANPC VSI for $V_{i a}^{*}>0$ (left) and $V_{i a}^{*}<0$ (right).
As was noted in Section II.A, the ANPC VSI is deactivated for $I_{R S S} \geq 0$. This is realised here by forcing $\left(V_{V S I, a c t}-V_{R S S}\right)$ to zero and resetting the integrator within the PI controller for the constant DC voltage control.

\section{LOW-FIDELITY MODEL OF REVERSIBLE SUBSTATION}

\section{A. Simplification of Reversible Substation}

In order to reduce computation burden, a low-fidelity model focusing on the TPSS-level simulation is developed to simplify the representation of the RSS, as shown in Fig. 5. The 12-pulse diode rectifier transformer is simplified into a CVS in series with a diode which prevents the braking current from passing through the rectifier. The input signal of the CVS, i.e. the output voltage $V_{\text {reco }}$ of the rectifier, is determined by the output current $I_{\text {reco }}$ based on its non-linear output characteristic as plotted in Fig. 6. It shows that $V_{\text {reco }}$ rapidly declines from $\sqrt{2} \times 1225 \mathrm{~V}$ when the current begins to flow into the DC TPSS [21], and then relatively slowly reduce with the further increase of $I_{\text {reco }}$. In addition, a 10 $m \Omega$ resistor is placed in the CVS branch to approximate the internal resistance of the AC-to-DC conversion, which helps reduce the difference in the $\mathrm{AC}$ power supply simulated between the low-fidelity and high-fidelity models.

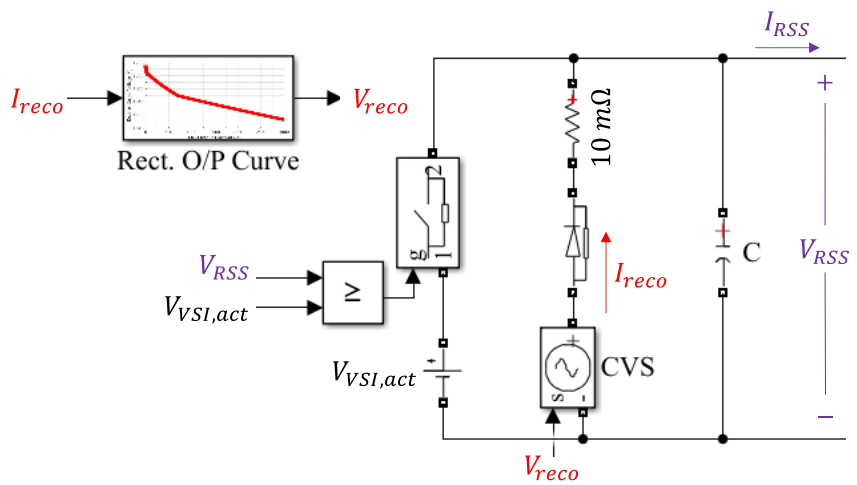

Fig. 5. The simplified representation of the RSS in a low-fidelity model.

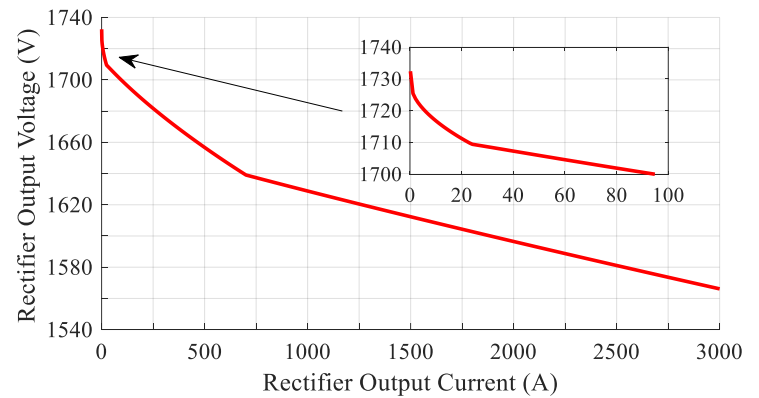

Fig. 6. The output curve of the modelled 12-pulse rectifier transformer.

To reflect the VSI control as described in Section II.B, a DC voltage source of $V_{V S I, a c t}$ is connected in parallel with the CVS branch, and placed alongside an ideal switch which is activated if $V_{R S S}$ is greater than or equal to $V_{V S I, a c t}$. In addition, the two series $60 \mathrm{mF}$ capacitors across the RSS in Fig. 1 are merged into a single $30 \mathrm{mF}$ capacitor, as shown in Fig. 5 .

The power exchange $P_{R S S}(\mathrm{~W})$ between AC and DC sides at the RSS is approximately calculated by (5) based on the voltage and current monitored at the RSS. A positive or negative value 
of $P_{R S S}$ indicates the AC power transferred to or fed by the DC TPSS respectively.

$$
P_{R S S}= \begin{cases}V_{\text {reco }} \cdot I_{\text {reco }} & \text { for } I_{R S S} \geq 0 \\ V_{V S I, a c t} \cdot I_{R S S} \cdot f\left(I_{R S S}\right) & \text { for } I_{R S S}<0\end{cases}
$$

where $f(\cdot)$ is the DC-to-AC conversion efficiency inclusive of transformer losses. It varies with the input power and the input voltage of the VSI [22] or with the input current under a specific input voltage. Given the DC input voltage being maintained at $V_{V S I, a c t}=1780 \mathrm{~V}$ in the braking mode, the efficiency curve of the ANPC VSI inclusive of transformer losses is plotted in Fig. 7 where a maximum efficiency is achieved at around $150 \mathrm{~A}$.

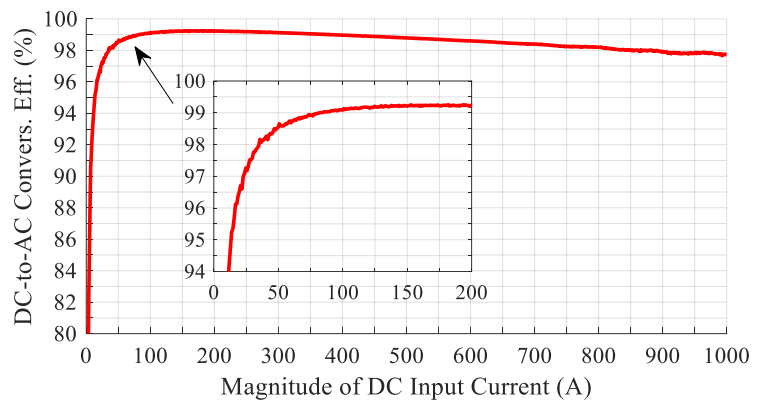

Fig. 7. The efficiency curve of the ANPC VSI inclusive of transformer losses.

\section{B. Overhead Catenary Line and Train Models}

The resistance of a line segment between the RSS and a train will vary with the train movement along the line. The segment length inferred from the train position (i.e. the integral of train speed over time) is multiplied by a resistance of $0.17 \Omega$ per $\mathrm{km}$ to compute the segment resistance. The variable resistance of the line segment (see Fig. 8) is modelled here with an accuracy of $10 \mu \Omega$ by switching the series connected resistors ranging from 1-4 $\Omega$ to $10-40 \mu \Omega$. Please refer to [5] where variable resistance modelling and examples are described.

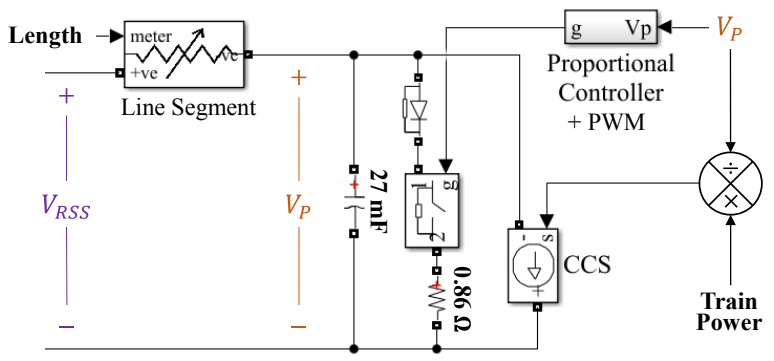

Fig. 8. The circuit diagram of the resistive line segment and the train model.

Since this paper focuses on the RSS simulation, the train is simply modelled here by combining a controlled current source (CCS) with a resistive braking chopper [5], as shown in Fig. 8. The input signal of the CCS, i.e. the current regenerated or absorbed by the train, is determined as the ratio of its electrical power to the simulated pantograph voltage $V_{P}$. The train power is calculated from the speed profile and train properties based on a set of vehicle dynamic equations. For details of the train power calculation, the reader is referred to [5, 23]. Fig. 9 shows the presumed speed profile of a particular train and the resulting train power time series. The power consumption of on-board auxiliary systems is neglected here for simplicity, though it can be estimated from on-board voltage and current measurements.

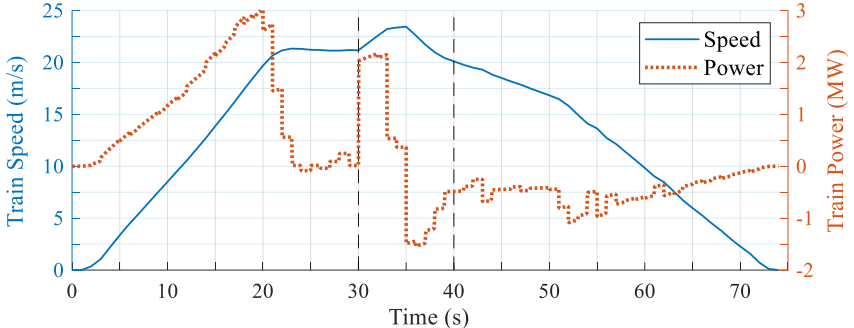

Fig. 9. The presumed speed $(\mathrm{m} / \mathrm{s})$ and the resulting power $(\mathrm{MW})$ consumed $(+)$ or regenerated (-) by a particular train.

In the regenerative braking mode, the train current fed to the line will increase $V_{P}$. Once the monitored $V_{P}$ exceeds a specific level of $1930 \mathrm{~V}$, the on-board braking chopper is activated such that the excess braking energy is dissipated in braking resistors, avoiding violation of the over-voltage limit. The (de)activation of the braking resistor with an equivalent resistance of $0.86 \Omega$ is determined by the PWM which compares a carrier wave with the output of a proportional controller driven by the exceedance of $V_{P}$ over $1930 \mathrm{~V}$ [24]. The ripples in $V_{P}$ are attenuated by a 27 $\mathrm{mF}$ capacitor at the input stage of the train.

\section{RESUltS AND MODEL VALIDATION}

The high- and low-fidelity models are developed here using Matlab/Simulink [25], and are both simulated at a time step of 5 us based on the presumed train speed profile during $30 \mathrm{~s}-40 \mathrm{~s}$ in Fig. 9. The computation time used by the two models is around $220 \mathrm{~s}$ and $45 \mathrm{~s}$ respectively, i.e. nearly a $80 \%$ reduction in the low-fidelity model. (The computer being used has a 64-bit operating system, 8 GB of RAM and an Intel Core i7-4500, 2.4 $\mathrm{GHz}$ processor). In this section, the power exchange and $\mathrm{DC}$ voltage transients at the RSS simulated by the two models are compared first, followed by an evaluation of the total harmonic distortion of the three-phase AC current in the braking mode.

\section{A. DC Voltage Transient Simulation}

Fig. 10 shows the DC voltage $V_{R S S}$ at the RSS simulated by the two models which are very close for most of the time. In the traction mode over $30 \mathrm{~s}-35 \mathrm{~s}, V_{R S S}$ is largely determined by the rectifier's output characteristic (see Fig. 6) where the output voltage decreases with the growth of the output DC current.

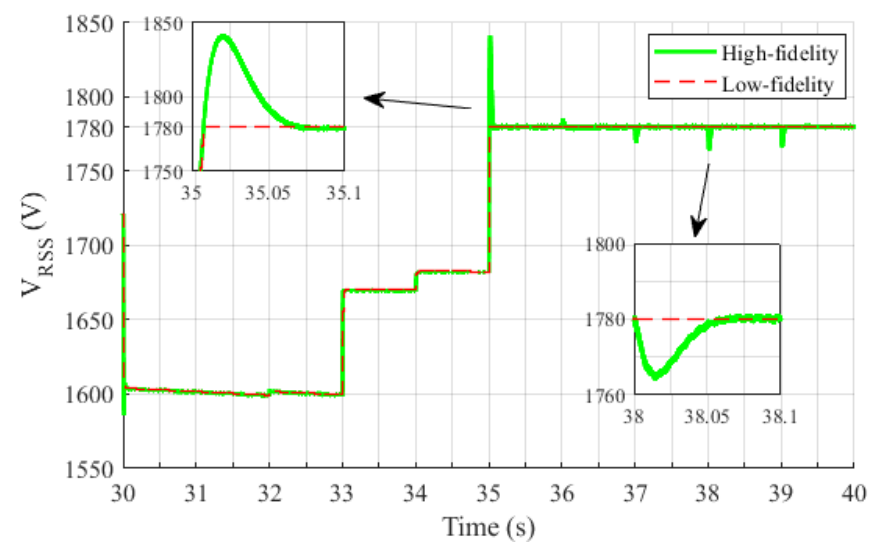

Fig. 10. $V_{R S S}$ across the RSS simulated by the two models over $30 \mathrm{~s}-40 \mathrm{~s}$.

As the train begins to brake at $35 \mathrm{~s}, V_{R S S}$ quickly increasing beyond $V_{V S I, a c t}$ activates the VSI to feed the braking power to 
the AC side. The high-fidelity simulation indicates that $V_{R S S}$ is adjusted back to $V_{V S I, a c t}$ and then maintained at around $V_{V S I, a c t}$ $=1780 \mathrm{~V}$ under the constant DC voltage control. Then some visible $V_{R S S}$ fluctuations are shown to occur when the recovered braking power changes stepwise. Since the low-fidelity model uses a DC voltage source to simply represent the constant DC voltage control, it cannot reflect the transient $V_{R S S}$ changes.

\section{B. Power Exchange Simulation}

The 1-ms average data of the AC power supplied to (+ve) or fed by (-ve) the DC TPSS through the RSS simulated by the two models is compared in Fig. 11. The inclusion of the rectifier's output characteristic and the DC-to-AC conversion efficiency in the low-fidelity model is considered to be the main contribution to its consistency with the high-fidelity simulation. Though there are some slight deviations in the $\mathrm{AC}$ power simulation due to the fluctuations of $V_{R S S}$ at times of the recovered braking power changing stepwise, their short durations (i.e. about $50 \mathrm{~ms}$ ) would have little impact on the total energy calculation.

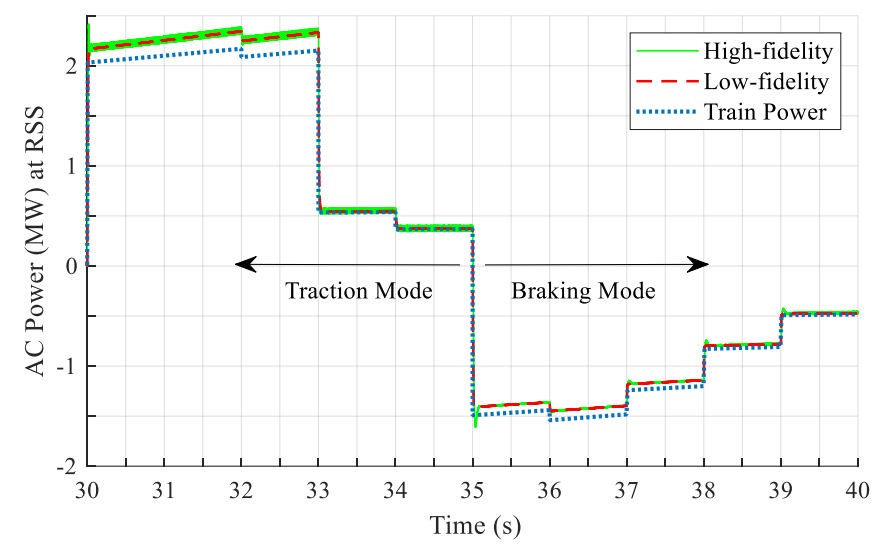

Fig. 11. The 1-ms average power (MW) supplied by (+ve) or injected into (-ve) the $\mathrm{AC}$ grid via the RSS and the train power over $30 \mathrm{~s}-40 \mathrm{~s}$.

Fig. 11 also plots the train power over the same 10-s period which is smaller (or higher) in magnitude than the $\mathrm{AC}$ power in the traction (or braking) mode due to the converter efficiency as well as the power loss on the line segment resistor. Furthermore, the differences increase with the $\mathrm{AC}$ power level since the growth of the DC current flowing across the line segment results in greater transmission losses. In addition, most of the train braking power is shown to be recovered by the RSS and injected into the AC grid. The total energy fed-back-to the AC grid and the total train braking energy over each of the last five seconds are compared in Fig. 12. It is evaluated that greater than $94 \%$ of the total train braking energy is recovered in the simulation.

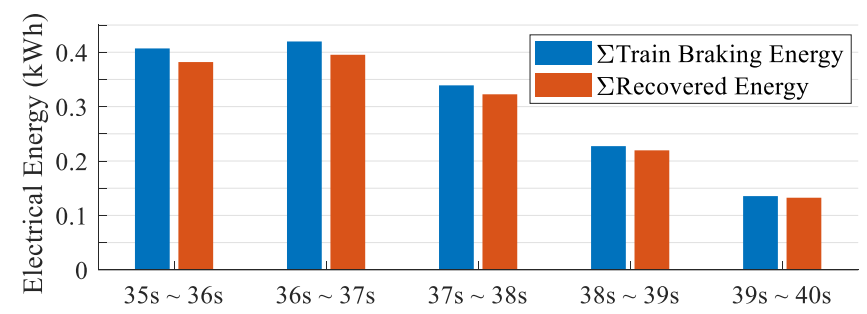

Fig. 12. The total train braking energy $(\mathrm{kWh})$ and total recovered energy $(\mathrm{kWh})$ over each second in the braking mode.

\section{AC Current Transient Simulation}

The high-fidelity simulation of three-phase AC current $I_{g}^{3 \phi}$ in the braking mode over 5 particular subsequent cycles between $35.1 \mathrm{~s}$ and $35.2 \mathrm{~s}$ is plotted in Fig. 13. To evaluate the harmonic distortion of the AC current fed by the RSS, the fast Fourier transform [26] is applied to the current waveform, e.g. of phase A in the first cycle, as shown in Fig. 14. (It has been examined that each phase current has a similar spectrum in the same cycle). The current total harmonic distortion (THD) is evaluated to be around $3.82 \%$, which is within the limit of $5 \%$ as required by IEEE Standard 519 [27]. The current THD mainly comes from the components around $4 \mathrm{kHz}$, i.e. twice the switching frequency of the IGBTs within the VSI. This is because the PWM strategy applied to the ANPC VSI results in a natural doubling of the apparent switching frequency, as was noted in Section II.B.

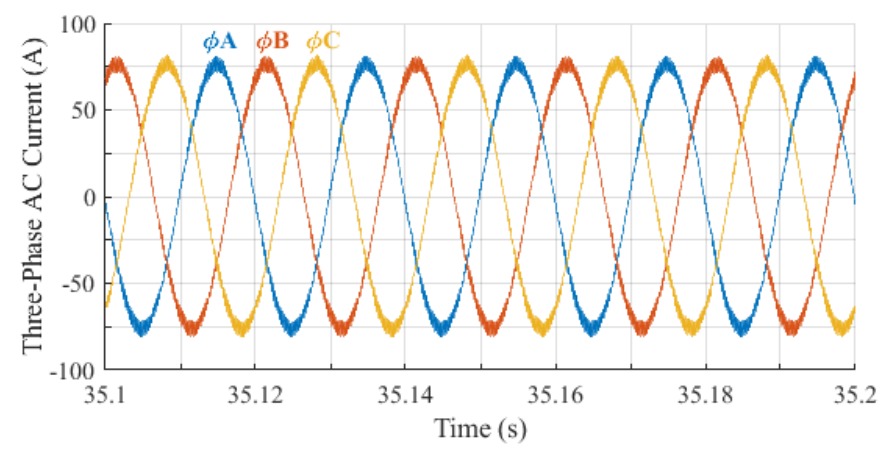

Fig. 13. The waveforms of three-phase AC current fed by the RSS in the braking mode over $35.1 \mathrm{~s}-35.2 \mathrm{~s}$.

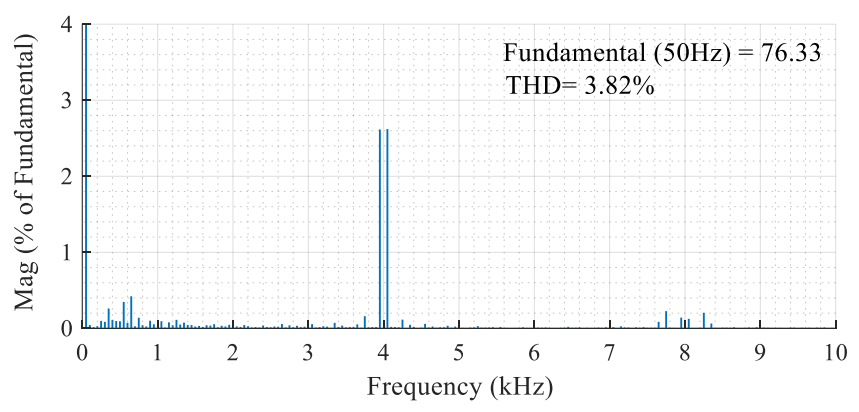

Fig. 14. The frequency spectrum ( $\%$ of $50 \mathrm{~Hz}$ component) of the current along phase A in a particular cycle over $35.1 \mathrm{~s}-35.12 \mathrm{~s}$ in braking mode.

\section{CONCLUSIONS AND FUTURE WORK}

The recovery of the braking energy by an RSS is expected to increase the energy efficiency of a DC TPSS. To assist in assessing influences of an RSS on power quality and system stability and quantifying the braking energy recovery, this paper has developed two Simulink models with different fidelities to simulate the function of an RSS in a DC TPSS. A high-fidelity model focusing on the electrical transient simulation replicated the topology of a particular RSS consisting of a 12-pulse diode rectifier and an antiparallel ANPC VSI which was controlled here to maintain a constant DC voltage in the braking mode. In order to reduce the computation burden in the power flow simulation during a long time period, a low-fidelity model was further developed where the converters were simplified into a CVS and a parallel DC voltage source which reflected the non- 
linear output characteristic of the rectifier and the constant DC voltage control method applied to the VSI respectively.

The high- and low-fidelity models have been tested based on a simplified DC TPSS where a single RSS supplied a single train via an overhead line which was modelled as a pure variable resistor. The computation time used by the high-fidelity model was reduced by about $80 \%$ in the low-fidelity model. In addition, the two models showed good consistency in the simulation of the power exchange and DC voltage transients at the RSS for the majority of the time. Compared to the low-fidelity model, the high-fidelity simulation was able to reflect transient changes of the DC voltage at the RSS under the constant DC voltage control method, especially at the start of the braking mode and when the recovered braking power changes stepwise. Furthermore, the high-fidelity simulation permitted evaluating the THD of the AC current fed by the RSS, which was around $3.82 \%$ in a particular $0.02-$ s cycle in this study.

Building on the present work, the low-fidelity model will be tested at different simulation time steps to address the trade-off in the time step between the accuracy of power flow simulation and computation time. Furthermore, both high- and low-fidelity models will be extended to an entire DC TPSS to assess the RSS performance in multiple train operation. Moreover, the RSS control algorithm implemented here can be adjusted to reflect a specific practical RSS regulation, permitting validation of the high-fidelity model based on field measurements.

\section{ACKNOWLEDGMENT}

The research was developed under the 16ENG04 MyRailS Project which received funding from the EMPIR programme cofinanced by the Participating States and from the European Union's Horizon 2020 Research and Innovation Programme. Support for the work described in this paper is gratefully acknowledged from the partners of the MyRailS project.

\section{REFERENCES}

[1] Moving towards Sustainable Mobility - a Strategy for 2030 and beyond for the European Railway Sector, International Union of Railways (UIC), Summary Rep., Paris, 2012.

[2] M. Popescu and A. Bitoleanu, "A review of the energy efficiency improvement in DC railway systems," Energies, vol. 12, no. 6, paper no. 1092, pp. 1-25, 2019

[3] M. Khodaparastan, A. Mohamed, and W. Brandauer, "Recuperation of regenerative braking energy in electric rail transit systems," IEEE Trans. Intell. Transp. Syst., vol. 20, no. 8, pp. 2831-2847, Aug. 2019.

[4] A. Gonzalez-Gil, R. Palacin, and P. Batty, "Sustainable urban rail systems: strategies and technologies for optimal management of regenerative braking energy," Energy Convers. Manag., vol. 75, pp. 374-388, Nov. 2013.

[5] F. Fan and B.G. Stewart, "Power flow simulation of DC railway power supply systems with regenerative braking," in Proc. 2020 IEEE $20^{\text {th }}$ Mediterranean Electrotechnical Conf. (MELECON), Palermo, Italy, Jun. 2020, pp. 87-92.

[6] P. Arboleya, B. Mohamed, I. El-Sayed, "DC railway simulation including controllable power electronic and energy storage devices," IEEE Trans. Power Syst., vol. 33, no. 5, pp. 5319-5329, Sep. 2018.

[7] Z. Tian, S. Hillmansen, C. Roberts, et al., "Energy evaluation of the power network of a DC railway system with regenerating trains," IET Electr. Syst. Transp., vol. 6, no. 2, pp. 41-49, Jun. 2016
[8] H. Alnuman, D. Gladwin, and M. Foster, "Electrical modelling of a DC railway system with multiple trains," Energies, vol. 11, no. 11, paper no. 3211, pp. 1-20, Nov. 2018

[9] G. Zhang, Z. Tian, P. Tricoli, S. Hillmansen, and Z. Liu, "A new hybrid simulation integrating transient-state and steady-state models for the analysis of reversible DC traction power systems," Int. J. Electr. Power Energy Syst., vol. 109, pp. 9-19, Jul. 2019.

[10] C.H. Bae, M.S. Han, Y.K. Kim, C.Y. Choi, and S.J. Jang, "Simulation study of regenerative inverter for DC traction substation," in Proc. 2005 Int. Conf. Electr. Mach. Syst., Nanjing, China, Sep. 2005, pp. 1-5.

[11] G. Zhang, J. Qian, and X. Zhang, "Application of a high-power reversible converter in a hybrid traction power supply system," Appl. Sci., vol. 7, no. 3, paper no. 282, pp. 1-19, Mar. 2017.

[12] Y. Krim, K. Almaksour, H. Caron, et al., "Comparative study of two control techniques of regenerative braking power recovering inverter based DC railway substation," in Proc. $202022^{\text {nd }}$ European Conf. Power Electron. Appl., Lyon, France, Sep. 2020, pp. 1-9.

[13] M. Schweizer, T. Friedli, and J.W. Kolar, "Comparative evaulation of advanced three-phase three-level inverter/converter topologies against two-level systems," IEEE Trans. Ind. Electron., vol. 60, no. 12, pp. 55155527, Dec. 2013

[14] T. Brückner, S. Bernet, and H. Güldner, "The active NPC converter and its loss-balancing control," IEEE Trans. Ind. Electron., vol. 52, no. 3, pp. 855-868, Jun. 2005.

[15] D. Barater, C. Concari, G. Buticchi, et al., "Performance evaluation of a three-level ANPC photovoltaic grid-connected inverter with $650-\mathrm{V} \mathrm{SiC}$ devices and optimized PWM," IEEE Trans. Ind. Appl., vol. 52, no. 3, pp. 2475-2485, Jun. 2016.

[16] Z. Tian, G. Zhang, N. Zhao, et al., "Energy evaluation for DC rialway systems with inverting substations," in Proc. 2018 IEEE Int. Conf. Electr. Syst. Aircraft, Railway, Ship Propulsion and Road Veh. \& Int. Transport. Electrific. Conf., Nottingham, UK, Nov. 2018, pp. 1-6.

[17] S.Z. Abbas, "Simulation, implementation and testing of three-phase controlled power inverter behavior," Master thesis, The Polytechnic Univ. Milan, Apr. 2016.

[18] S. Chattopadhyay, M. Mitra, and S. Sengupta, "Clarke and Park transform," in Electric Power Quality Power Systems, Ch. 12, pp. 89-96, Springer: Dordrecht, Mar. 2011.

[19] M. Khodaparastan and A. Mohamed, "Modeling and simulation of a reversible substation for recuperation of regenerative braking energy in rail transit systems," in Proc. IEEE Transport. Electrific. Conf. Expo., Detroit, USA, Jun. 2019, pp. 1-5.

[20] D. Floricau, E. Floricau, and M. Dumitrescu, "Natural doubling of the apparent switching frequency using three-level ANPC converter," in Proc. 2008 Int. School on Nonsinusodial Currents and Compensation, Lagow, Poland, Jun. 2008, pp. 1-6.

[21] P. Pozzobon, "Transient and steady-state short-circuit currents in rectifiers for DC traction supply," IEEE Trans. Veh. Technol., vol. 47, no. 4, pp. 1390-1404, Nov. 1998.

[22] N.M. Pearsall, "Introduction to photovoltaic system performance," in The Performance of Photovoltaic (PV) Systems, Modelling, Measurement and Assessment, Elsevier: Duxford, 2017, pp. 1-19.

[23] M. Saleh, O. Dutta, Y. Esa, and A. Mohamed, "Quantitative analysis of regenerative energy in electric rail traction systems," in Proc. IEEE Ind. Appl. Soc. Annual Meeting, Cincinnati, USA, Oct. 2017, pp. 1-7.

[24] The MathWorks, Inc., DC Bus - Implement DC bus model that includes resistive braking chopper, 2020. Available: Implement DC bus model that includes resistive braking chopper - Simulink (mathworks.com)

[25] MATLAB Release, The MathWorks, Inc., Natick, MA, USA, 2019.

[26] P. Heckbert, Notes 3 Copmut. Graphics 2, 15-463, Fourier transforms and the fast Fourier transform (FFT) algorithm, Carnegie Mellon Univ., Pittsburgh, USA, 1998.

[27] IEEE Recommended Practice and Requirements for Harmonic Control in Electric Power Systems, IEEE Standard 519, 2014. 